\title{
Métodos de interpolação espacial para o mapeamento da precipitação pluvial
}

\author{
Marcelo R. Viola ${ }^{1}$, Carlos R. de Mello ${ }^{2}$, Daniel B. F. Pinto ${ }^{2}$, José M. de Mello ${ }^{3}$ \& Leo F. Ávila ${ }^{2}$
}

\section{RESUMO}

A espacial ização de variáveis climáticas, notadamente a precipitação pluvial, necessita de estudos constantes, visando ao aperfeiçoamento de interpoladores e desenvolvimento de mapas sem tendência. Objetivou-se, neste contexto, avaliar o desempenho dos interpoladores krigagem (KG), a partir do melhor modelo de semivariograma, cokrigagem (CA), introduzindo a altitude como variável secundária, modelagem estatística (ME), na qual a precipitação média pode ser estimada a partir de coordenadas geográficas, e inverso do quadrado da distância (IQ D), para espacialização da precipitação média mensal, precipitação média do período seco e precipitação média anual, em Minas Gerais; para isto se utilizaram informações de 232 postos pluviométricos para modelagem e de 70 para validação, com base no erro médio absoluto, além de um modelo digital de el evação com resolução de $270 \mathrm{~m}$. Q uanto à avaliação dos métodos de interpolação, constatou-se bom desempenho das metodologias abordadas, com erro absoluto médio variando de 12,84 a 19,96\%, com destaque para a cokrigagem, que obteve menor erro em $50 \%$ das situações analisadas.

Palavras-chave: modelagem espacial, climatologia, interpoladores

\section{Spatial interpolation methods for mapping of rainfall}

\begin{abstract}
The mapping of weather elements, especially rainfall, needs constant studies to improve the performance of interpolators, and to obtain unbiased maps. This work aimed to evaluate the performance of some spatial interpolators for mean monthly rainfall, mean rainfall during the dry season and mean annual rainfall in the Minas Gerais State. For that, the ordinary kriging was evaluated and compared, after the semi-variogram modeling, co-kriging (introducing the altitude above sea level as a secondary variable), statistical modeling in which the mean precipitation can be estimated from geographical coordinates, and inverse square distance. In this study, data sets were evaluated from 232 pluviometric stations, in the Minas Gerais area, to apply each one of the interpolators mentioned and 70 stations to evaluate the performance that was conducted on the basis of absolute mean error. In addition, a digital elevation model, with a resolution of $270 \mathrm{~m}$, was applied. The interpolators have shown good performance, with mean errors varying from 12.84 to $19.96 \%$, the cokriging method presenting a smaller absolute mean error in $50 \%$ of the situations evaluated.
\end{abstract}

Key words: spatial modeling, climatology, interpolators 


\section{INTRODUÇÃO}

O Estado de Minas Gerais apresenta vasta extensão territorial, associada a longas cadeias montanhosas, proporcionando-lhe um regime pluvial diversificado. Neste contexto, o estudo da distribuição espacial das chuvas é fundamental à gestão dos recursos hídricos visto que, em termos do ciclo hidrológico, a mesma pode ser considerada a entrada efetiva de água na bacia hidrográfica e sua distribuição espaço-temporal, conjuntamente com outros fatores, como o solo e seu uso, condicionam a resposta hidrológica da bacia.

Conciliado a isto, na simulação do comportamento hidrológico por modelos físico-matemáticos, nos quais a precipitação é tida como variável de entrada, algum grau de discretização espacial da bacia hidrográfica é requerido e, assim, a estimativa da média espacial fica dependente de métodos de interpolação.

Tradicionalmente, o monitoramento da precipitação é realizado em postos de coleta pontuais, o que determina a utilização de métodos de interpolação espacial para o seu mapeamento, dentre os quais se destacam o interpolador geoestatístico e o inverso do quadrado da distância (Mello et al., 2003; Cecílio \& Pruski, 2003; Carvalho \& Assad, 2005). Neste contexto, uma demanda técnico-científica atual e relevante consiste na avaliação do desempenho de interpoladores no mapeamento de variáveis climáticas. Estudos recentes abordando técnicas que utilizam a reconhecida correlação existente entre a precipitação e o relevo, têm apresentado resultados relevantes (Martinez-Cob, 1996; Lloyd, 2005; Carrera-Hernandez \& Gaskin, 2007; Fenille \& Cardim, 2007), estimulando a verificação de sua potencialidade no Estado de Minas Gerais, dada a importância das condições topográficas nas suas condições climáticas, especialmente pluvial (Mello et al., 2007).

O mapeamento da precipitação pluvial e de outras variáveis ambientais é de fundamental importância no setor agroflorestal, com destaque para ações diretamente associadas à modelagem da produção florestal, como em modelos ecofisiológicos. Tais modelos permitem compreender, predizer e controlar todo o sistema florestal, especificamente auxiliando no zoneamento florestal e mapeamento da produção, consistindo em uma ferramenta de planejamento indispensável para as empresas florestais as quais contribuem, de forma consistente, com a economia do Estado de Minas Gerais; no entanto, em termos climatológicos, uma investigação mais aprofundada sobre o desempenho dos interpoladores mais aplicados ao mapeamento, precisa ser conduzida, uma vez que os trabalhos desenvolvidos até o momento não demonstram nem concluem, de forma efetiva, o melhor ou o mais indicado processo de interpolação espacial.

Propôs-se, então, avaliar o desempenho dos interpoladores espaciais krigagem $(\mathrm{KG})$ e cokrigagem (CA), tendo a altitude como variável secundária, modelos estatísticos (ME) que permitem a estimativa da precipitação cujas variáveis de entrada são as coordenadas geográficas (latitude e longitude) e altitude, desenvolvidos por Mello \& Silva (2009) e inverso do quadrado da distância (IQD), para o mapeamen- to da precipitação anual, mensal e no período seco, em que o Estado de Minas Gerais é reconhecido como referência territorial.

\section{MATERIAL E MÉTODOS}

O Estado de Minas Gerais se encontra na região Sudeste do Brasil, com área aproximada de $586.753 \mathrm{~km}^{2}$, onde ocorre importante variabilidade climática prevalecendo, ao $\mathrm{Sul} / \mathrm{Su}-$ deste e locais de elevada altitude, clima Cwb/Cwa pela classificação proposta por Köppen, com invernos frios e verões brandos e chuvosos, clima Aw nas regiões do Triângulo Mineiro, Leste, Norte e Vale do Jequitinhonha, com invernos brandos e verões quentes e chuvosos, além de clima BSw na região do extremo Norte de Minas, com características semiáridas (Antunes, 1986).

O banco de dados utilizado possui 302 séries históricas de precipitação diária, obtidas junto ao Sistema de Informações Hidrológicas (HidroWEB) da Agência Nacional de Águas (ANA), das quais 232 foram aplicadas nos diferentes métodos de interpolação testados e 70 reservadas para análise do desempenho dos mesmos. Estudos recentes abrangendo o mapeamento da precipitação apontam para melhorias nos resultados com a utilização da altitude como variável secundária, obtida a partir de modelos digitais de elevação (MDE). Apresenta-se, na Figura 1A, a distribuição espacial dos postos pluviométricos e, na Figura 1B, o MDE com resolução de $270 \mathrm{~m}$.

Os interpoladores espaciais foram aplicados às precipitações médias mensais de setembro, outubro, novembro, dezembro, janeiro, fevereiro, março e abril, à precipitação média anual e à precipitação total média do período seco (maio a agosto).

Desenvolveu-se, inicialmente, um estudo sobre o ajuste de modelos e métodos de ajuste de semivariograma ao comportamento da precipitação, visando posterior aplicação aos interpoladores geoestatísticos. Segundo Vieira (2000), este interpolador pondera os vizinhos do ponto a ser estimado, obedecendo aos critérios de não-tendenciosidade e mínima variância, o que lhe permite produzir melhores estimativas e, ainda segundo Junqueira Júnior et al. (2008), Assad et al. (2003) e Mello et al. (2003), a consideração da dependência espacial possibilita o controle de uma parcela do erro aleatório e a obtenção de bons resultados. O interpolador de krigagem, linear por definição, estima a variável interpolada na posição $\mathrm{p}\left(\mathrm{x}_{\mathrm{p}}\right)$, a partir do estabelecimento do peso de krigagem $(\lambda)$, de cada uma das $n$ observações vizinhas $\left(x_{i}\right)$, da seguinte forma:

$$
\mathrm{X}_{\mathrm{p}}=\sum_{\mathrm{i}=1}^{\mathrm{N}} \lambda_{\mathrm{i}} \cdot \mathrm{X}_{\mathrm{i}}
$$

entretanto, previamente à análise geoestatística, deve-se realizar a análise exploratória de dados visando verificar o atendimento a algumas pressuposições admitidas por esta metodologia, especialmente a não-tendenciosidade. Com este intuito se geraram gráficos de tendência, histogramas 
A.

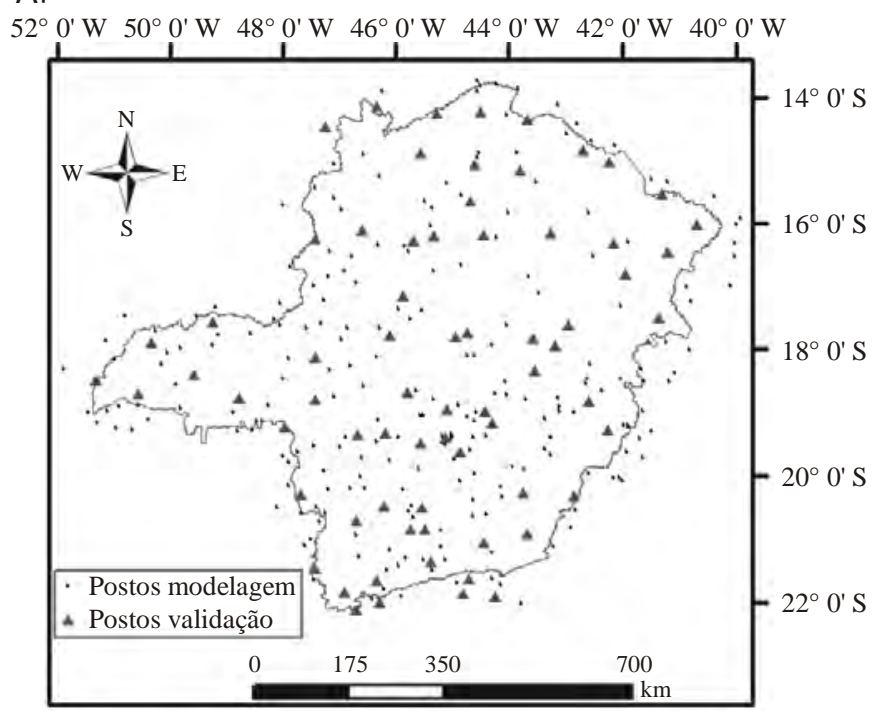

B.

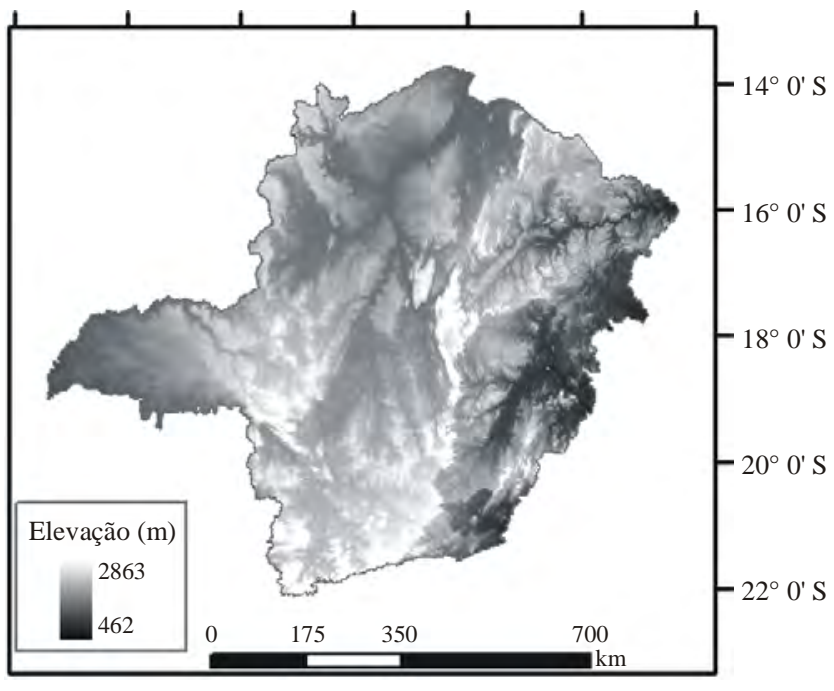

Figura 1. Localização dos postos pluviométricos aplicados ao estudo (A) e modelo digital de elevação (B)

de frequência das diferenças entre pares de pontos e análise de valores discrepantes ("outliers"), por meio de gráficos "boxplot".

Deve-se analisar, no mapeamento de fenômenos naturais, o comportamento da variável em diferentes direções visto que, caso se constate comportamento distinto nessas direções, o que caracteriza anisotropia, é conveniente se proceder à sua modelagem, visando melhor descrição do comportamento espacial do fenômeno (Mello et al., 2005). Assim, foram ajustados semivariogramas nas direções $0^{\circ}$, $45^{\circ}, 90^{\circ}$ e $135^{\circ}$, cujo comportamento foi comparado ao do semivariograma isotrópico, segundo procedimentos adotados por Mello et al. (2005).

Os modelos de semivariograma mais frequentes em estudos sobre a continuidade espacial da precipitação e abordados no presente estudo, são o esférico e o exponencial, ajustados ao semivariograma experimental, pelos métodos da máxima verossimilhança (MV) e dos mínimos quadrados ponderados (MQP) (Mello et al., 2008; Carvalho et al., 2004); contudo, o modelo a ser aplicado deve ser escolhido com base no erro médio produzido pela validação cruzada, que pode ser expresso da seguinte forma:

$$
\mathrm{EM}=\frac{\sum_{\mathrm{i}=1}^{\mathrm{n}}\left|\operatorname{Pobs}_{\mathrm{i}}-\mathrm{Pest}_{\mathrm{i}}\right| \cdot \operatorname{Pobs}_{\mathrm{i}}{ }^{-1}}{\mathrm{n}}
$$

em que Pobs e Pest são as precipitações observadas e estimadas, respectivamente. Em todas as etapas da análise geoestatística utilizou-se o programa R, através do pacote GeoR (Ribeiro Junior \& Diggle, 2001).

De acordo com Carvalho \& Queiroz (2002) e Angélico (2006), a cokrigagem é uma extensão multivariada da krigagem, que permite a utilização de variáveis secundárias densamente amostradas na espacialização de uma variável primária; sua vantagem, em se tratando do mapeamento da precipitação, se fundamenta na conhecida correlação existente entre esta variável e outras mais conhecidas, notadamente a altitude. Segundo Vieira (2000), quando o semivariograma cruzado demonstra dependência entre as variáveis, o que ocorre quando existe correlação estatística entre elas, é possível que se obtenha, com a cokrigagem, maior precisão que com a krigagem. Ainda de acordo com o autor, na cokrigagem a estimativa da variável na posição $\mathrm{p}\left(\mathrm{x}_{\mathrm{p}}\right)$ é obtida pela combinação linear das variáveis $\mathrm{x}_{1}$ e $\mathrm{x}_{2}$, ou seja:

$$
\mathrm{x}_{\mathrm{p}}=\sum_{\mathrm{i}=1}^{\mathrm{n} 1} \lambda_{1_{\mathrm{i}}} \cdot \mathrm{x}_{\mathrm{1}_{\mathrm{i}}}+\sum_{\mathrm{j}=1}^{\mathrm{n}_{2}} \lambda_{2 \mathrm{j}} \cdot \mathrm{x}_{2 \mathrm{j}}
$$

em que $\mathrm{n}_{1}$ e $\mathrm{n}_{2}$ representam o número de vizinhos de $\mathrm{x}_{1} \mathrm{e}$ $\mathrm{x}_{2}$, respectivamente, e $\lambda_{1}$ e $\lambda_{2}$ são os pesos de krigagem associados a cada valor de $\mathrm{x}_{1}$ e $\mathrm{x}_{2}$.

$\mathrm{O}$ terceiro interpolador avaliado foi o inverso da potência da distância, que realiza a estimativa da variável ao longo do espaço, ponderando pesos a cada um dos n postos mais próximos, o que é função do inverso de uma potência da distância, ou seja, quanto mais próximo do ponto a ser estimado maior o peso atribuído ao ponto amostrado. De acordo com Watson \& Philip (1985) e Mello et al. (2003), este interpolador é largamente utilizado com o expoente 2, com bons resultados, e com o qual recebe a denominação de inverso do quadrado da distância (IQD) razão pela qual se utilizou, neste trabalho, o inverso do quadrado da distância, operando com os 15 vizinhos mais próximos; sua expressão está apresentada na Eq. 4, em que d é a distância euclidiana entre a posição p a ser estimada e o i-ésimo local amostrado.

$$
\text { Pest }_{p}=\frac{\sum_{i=1}^{15} \operatorname{Pobs}_{i} \cdot d_{i}^{-2}}{\sum_{i=1}^{15} d_{i}^{-2}}
$$

A estimativa da precipitação com modelos estatísticos também representa uma alternativa potencial, dada à sua facilidade operacional e capacidade de estimar a precipitação para um local específico, reduzindo equívocos na interpretação e análise de mapas, os quais fornecem faixas de valores. Neste 
intuito, Mello \& Silva (2009) desenvolveram, por regressão linear múltipla, modelos estatísticos (ME) para predição da precipitação média mensal, anual e para o período seco no Estado de Minas Gerais, em função da latitude, longitude e altitude locais, caso em que não se considerou a existência de dependência espacial da variável precipitação. Detalhamento sobre os modelos, assim como maiores detalhes referentes à metodologia utilizada em sua formulação, podem ser obtidos no citado trabalho.

Utilizaram-se, para validação das 4 metodologias de interpolação abordadas, dados desconhecidos ao processo de modelagem e aplicação dos interpoladores, constituído de séries históricas de precipitação média mensal, anual e período seco de 70 postos pluviométricos. Segundo MartinezCob (1996) e Mello et al. (2003), esta é a melhor maneira de se estudar, comparativamente, metodologias de interpolação, haja vista que consiste de uma aplicação do processo a pontos desconhecidos validando, de forma consistente, as metodologias; desta forma se procedeu à validação, pela análise comparativa entre os dados amostrais e os estimados pelas distintas metodologias, tendo sido quantificado o erro médio (EM), conforme Eq. 2, e a tendência média do estimador (TE), segundo a Eq. 5, o qual, se positivo, expressa tendência de superestimativa e, se negativo, de subestimativa.

$$
\mathrm{TE}=\frac{\sum_{\mathrm{i}=1}^{\mathrm{n}}\left(\text { Pest }_{\mathrm{i}}-\text { Pobs }_{\mathrm{i}}\right) \cdot \text { Pobs }_{\mathrm{i}}^{-1}}{\mathrm{n}}
$$

A análise visual dos mapas gerados pelas metodologias visando verificar possíveis vantagens gráficas na reconstituição da distribuição espacial do fenômeno pelo interpolador, embora consista em uma análise subjetiva, é substancial, uma vez que possibilita a visualização do gradiente de variação do fenômeno no espaço, propiciado pelas distintas metodologias. Com este intuito se desenvolveram mapas de precipitação média anual, de acordo com as metodologias aplicadas, tendo-se empregado o programa ArcGis 9.2 Environmental Systems Research Institute (ESRI, 2004).

\section{RESULTADOS E DISCUSSÃO}

\section{Continuidade espacial da precipitação pluvial média no estado de Minas Gerais}

$\mathrm{Na}$ Tabela 1 se encontram as estatísticas básicas associadas às precipitações médias mensais, anual e período seco no Estado de Minas Gerais.

Nota-se grande variabilidade anual do regime pluvial com concentração de chuvas nos meses de novembro a março, com ápice do período chuvoso compreendido entre dezembro e janeiro, observando-se precipitação média mensal superior a $230 \mathrm{~mm}$; porém, de maio a agosto, no período seco, a precipitação foi da ordem de $6,5 \%$ da precipitação total anual marcando o regime pluvial na região pelo inverno seco. O coeficiente de variação $(\mathrm{CV})$ apresentou amplitude de 0,17 (novembro) a 0,60 (período seco), indicando maior variabilidade dos dados nos meses menos chuvosos, o que pode ser explicado devido, provavelmente, à presença de frentes frias mais intensas na região Sul, conduzindo a uma variabilidade maior das chuvas neste período, no Estado, uma vez que referidas frentes sofrem sensível enfraquecimento à medida em que avançam na direção Norte (Mello et al., 2007).

Apresentam-se, na Figura 2, os semivariogramas experimentais nas direções $0^{\circ}, 45^{\circ}, 90^{\circ}$ e $135^{\circ}$, juntamente com o semivariograma isotrópico (unidirecional), para a precipitação média do mês de janeiro (a), período seco (b) e anual (c) no Estado de Minas Gerais. Conforme se observa, há um comportamento aproximadamente comum entre o semivariograma isotrópico e os direcionais, fato também observado por Carvalho \& Assad (2005) e Carrera-Hernández \& Gaskin (2007) comum a todos os períodos em estudo. Segundo Mello et al. (2005), em condição de isotropia este é o modelo usado para modelar a variável de interesse.

$\mathrm{Na}$ Figura 3 se encontram os erros absolutos médios (EM) obtidos com base na validação cruzada, para a precipitação média mensal, no período seco e anual. A variação do erro foi de 7,6 a $17,3 \%$, obtidos para a precipitação média anual e para o mês de setembro, respectivamente. Quanto aos modelos de semivariograma, obteve-se melhor desempenho do modelo exponencial, com menor erro médio em 7 dos 10 períodos analisados. Para desenvolver o mapeamento pelo interpolador krigagem, visando comparar o desempenho com os demais, foram utilizados o modelo e o método de ajuste de semivariograma, que proporcionaram o menor EM.

Mello et al. (2008) conduziram um estudo referente ao comportamento espacial de chuvas intensas no Estado de Minas Gerais e concluíram sobre o melhor desempenho do modelo de semivariograma exponencial. Carvalho et al. (2004) avaliaram, pelo teste de normalidade de Filliben, os principais modelos geoestatísticos aplicados ao mapeamento da precipitação pluvial média anual no Estado de São Paulo e constataram que modelo o exponencial se sobressaiu em relação aos demais; esses resultados mostram que, para o mapeamento de variáveis climáticas pelo interpolador de krigagem, em especial a precipitação pluvial, a aplicação do modelo de semivariograma exponencial é recomendada.

Tabela 1. Estatísticas básicas associadas às precipitações médias mensais, anual e período seco, em Minas Gerais

\begin{tabular}{ccccccccccc}
\hline Estatísticas & Jan & Fev & Mar & Abr & PS & Set & Out & Nov & Dez & Anual \\
Média - mm & 234,79 & 160,41 & 152,45 & 68,23 & 83,24 & 44,47 & 105,26 & 186,86 & 247,87 & 1281,16 \\
Desvio-padrão & 58,03 & 49,59 & 35,86 & 17,45 & 50,27 & 18,44 & 24,13 & 31,42 & 51,87 & 241,25 \\
CV (\%) & 25 & 31 & 24 & 26 & 60 & 41 & 23 & 17 & 21 & 19 \\
\hline
\end{tabular}

$\mathrm{CV}=$ Coeficiente de Variação 
A.

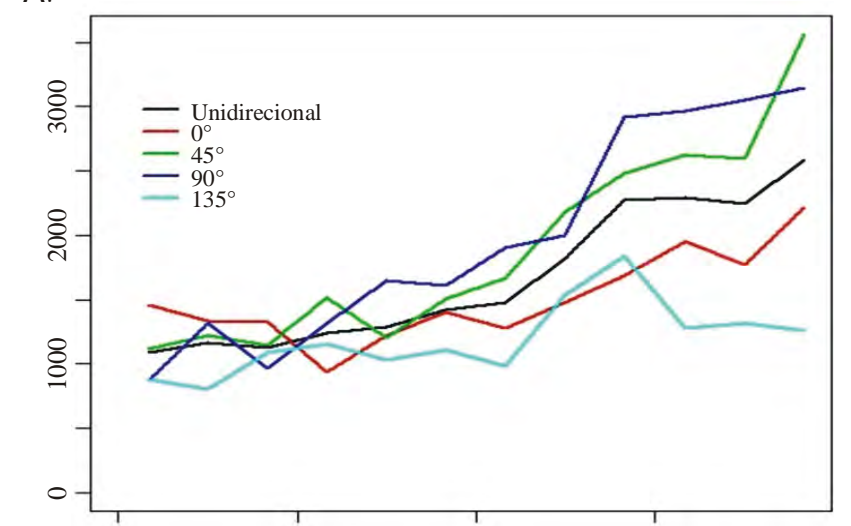

B.

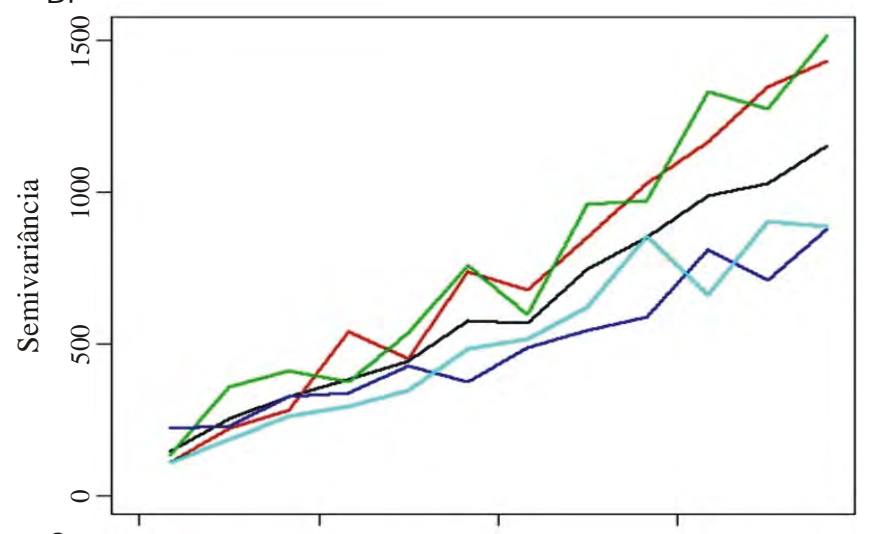

C.

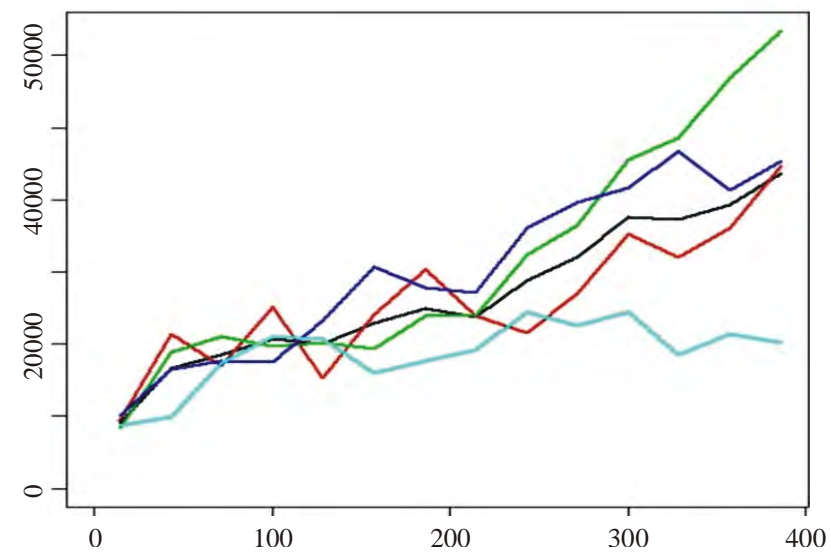

Figura 2. Semivariogramas direcionais e isotrópico para janeiro (A), período seco (B) e anual (C)

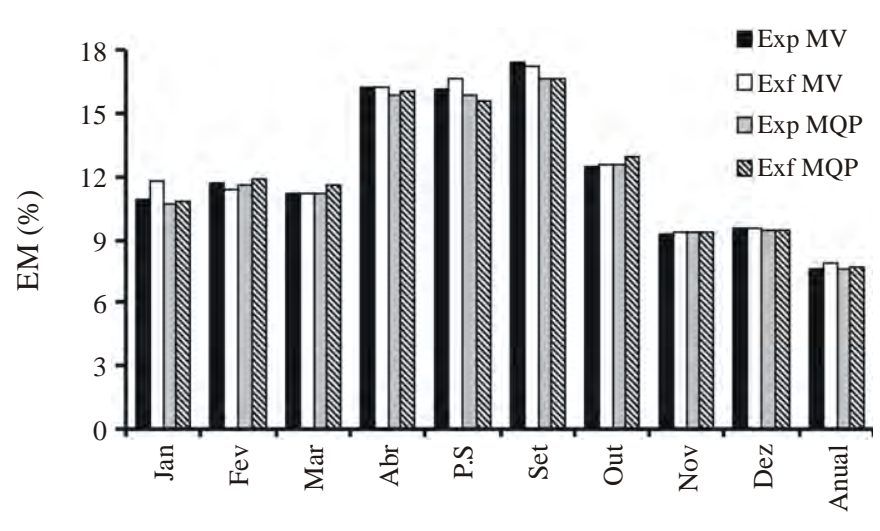

Figura 3. Erro absoluto médio (EM) obtido por validação cruzada para os modelos de semivariograma aplicados e respectivos métodos de ajuste

\section{Comparação dos interpoladores espaciais}

Utilizaram-se, para validação das 4 metodologias de interpolação estudadas, informações de 70 postos pluviométricos não aplicados à modelagem da continuidade espacial; já na Figura 4 se encontram as dispersões dos valores estima-

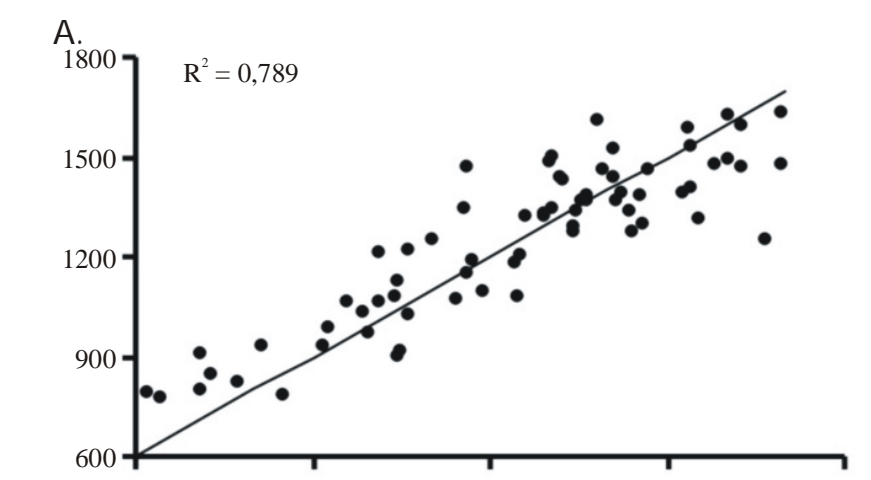

B.

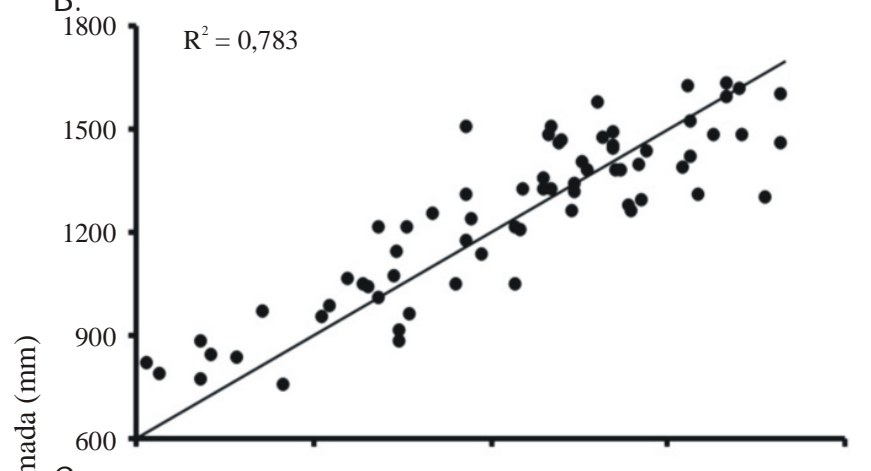

C

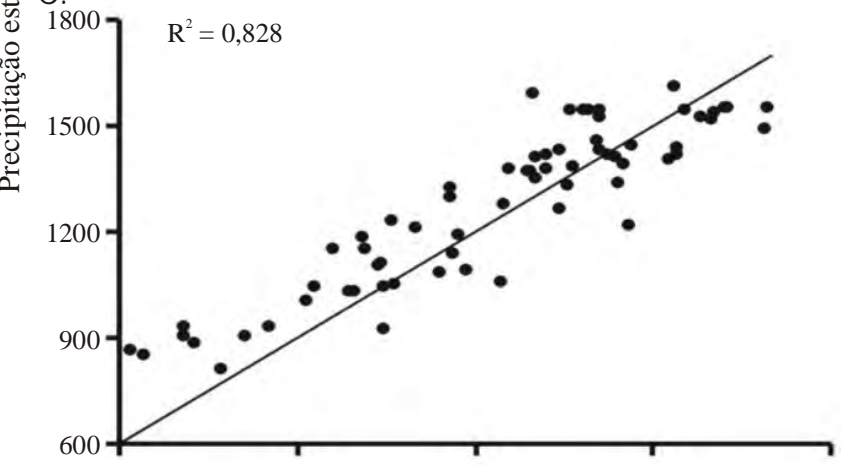

D.

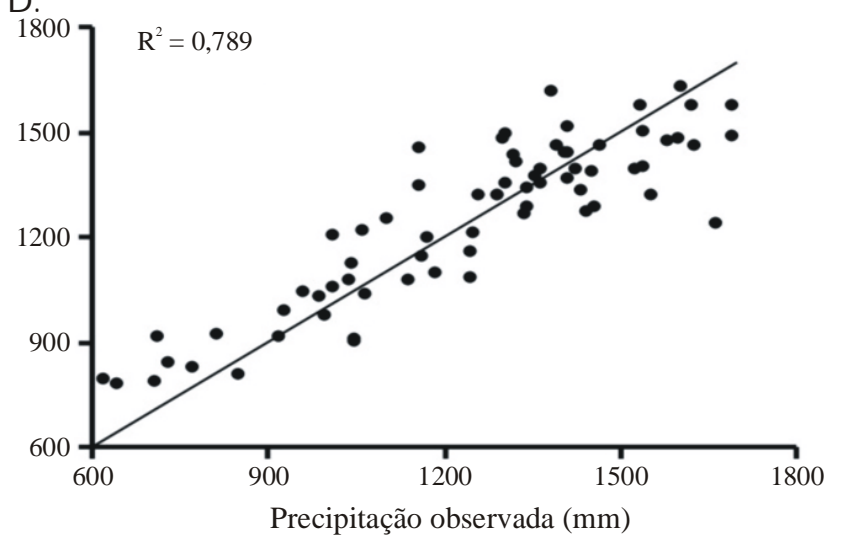

Figura 4. Dispersão dos valores estimados de precipitação média anual no Estado de M inas Gerais, em torno da reta 1:1, obtidos por krigagem (A), inverso do quadrado da distância (B), modelos estatísticos (C) e cokrigagem com altitude (D) 
dos para precipitação média anual em torno da reta 1:1, para os interpoladores estudados.

Todas as metodologias avaliadas mostraram baixa dispersão, fato reforçado pelo coeficiente de determinação $\left(\mathrm{R}^{2}\right)$, que variou de 0,783 a 0,828 para as metodologias IQD e ME, respectivamente. Ressalta-se que comportamento análogo foi encontrado para as precipitações médias mensais e período seco, com exceção dos meses de abril e novembro, quando se obtiveram valores de $\mathrm{R}^{2}$ variando de 0,46 a 0,60 e de 0,36 a 0,52 , respectivamente; o erro absoluto médio e a tendência média do estimador, obtidos entre os valores observados e os simulados para precipitação média mensal, anual e período seco, estão apresentados na Figura 5.

É possível observar pequenos erros de estimativa com valores médios inferiores a $17 \%$, com exceção do período seco, em que se observou erro médio entre os interpoladores de $29 \%$; contudo, a ocorrência do erro máximo de estimativa durante o período seco foi comum a todos os interpoladores, com valores de 18,89, 19,75, 58,67 e 18,69\% para krigagem, inverso do quadrado da distância, modelos estatísticos e cokrigagem, respectivamente. O maior erro nessa época decorre da maior variabilidade dos índices pluviométricos dificultando a reconstituição da continuidade espacial pelos interpoladores, e que pode ser afirmado com base no elevado coeficiente de variação obtido para este período, que foi de $60 \%$.

$\mathrm{O}$ interpolador geoestatístico krigagem, amplamente aplicado ao mapeamento de variáveis climáticas, apresentou erro absoluto médio entre os diversos períodos analisados de $13,11 \%$, tendo produzido o menor erro nos meses de fevereiro e setembro, de 10,57 e $16,82 \%$, respectivamente.

De maneira semelhante, o interpolador IQD apresentou erro médio de $13,11 \%$ e se sobressaiu em 2 dos 10 períodos analisados, com os menores erros médios para os meses de abril e dezembro, iguais a 15,41 e $10,31 \%$, respectivamente. Os modelos estatísticos gerados por Mello \& Silva (2009), apresentaram desempenho comparável com os demais interpoladores avaliados na maioria dos períodos estudados, com erro médio de $19,96 \%$, fornecendo o menor erro de estimativa no mês de janeiro, isto é, de $10,36 \%$; no entanto, em outubro, novembro e no período seco, se encontraram erros consideravelmente superiores aos obtidos pelos demais interpoladores, da ordem de 28,62, 20,36 e 58,67\%, respectivamente. Este comportamento se deve ao fato de tais modelos não considerarem a estrutura de dependência espacial e, no caso dos interpoladores geoestatísticos, estes apresentam variância mínima e não tendenciosidade (Vieira, 2000), permitindo reduzir parcela do erro aleatório associada à posição da amostra no espaço.

Para que se obtenham bons resultados com a cokrigagem, é necessário que alterações no comportamento da variável secundária possam explicar, ao menos parcialmente, alterações na variável primária. Uma avaliação preliminar sobre esta dependência pode ser realizada pelo coeficiente de correlação (r). Na Figura 6 estão os coeficientes de correlação entre altitude e precipitação para os 10 períodos estudados. De acordo com Santos (2007), o coeficiente de correlação é dito fraco em situações em que $0,1 \leq \mathrm{r}<0,5$ e moderado entre 0,5 e 0,8 . Desta maneira se observa que abril, novembro e
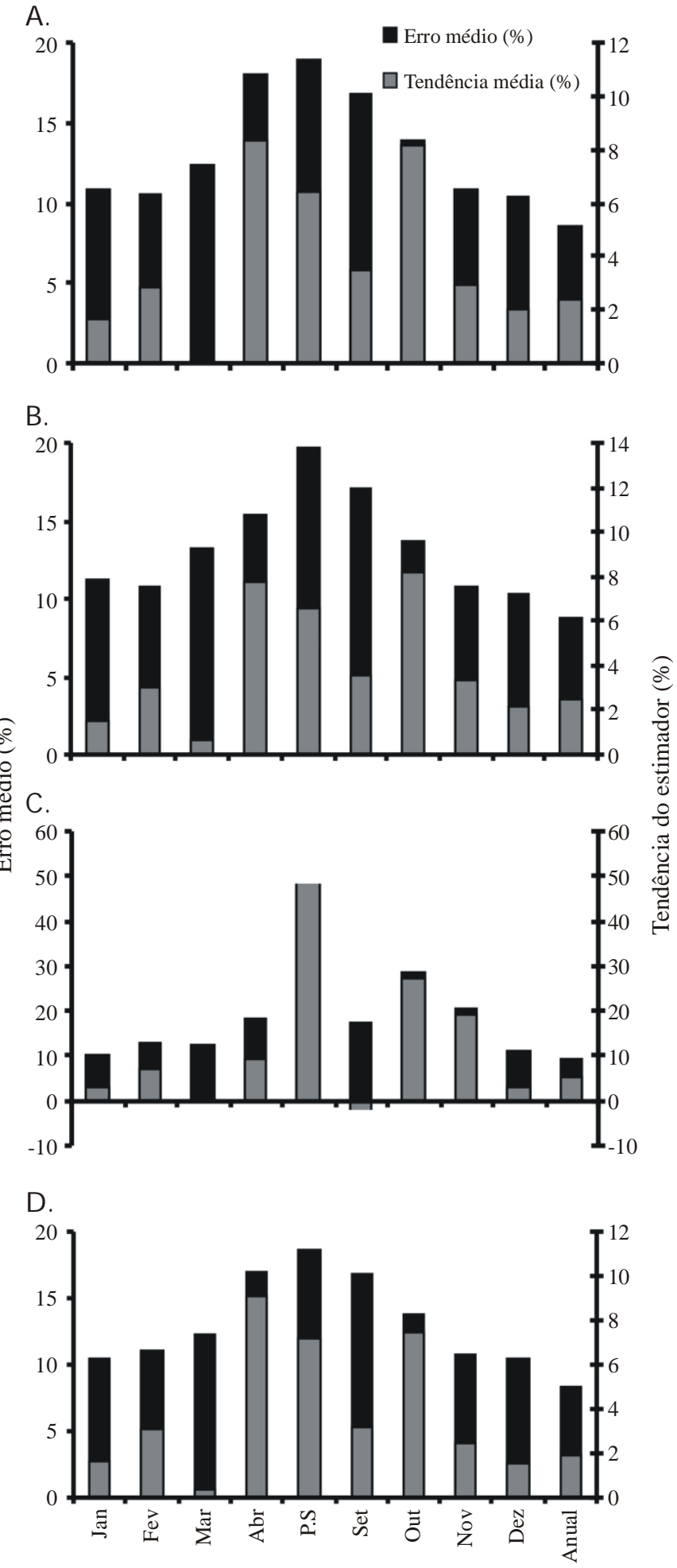

Figura 5. Erro absoluto médio e tendência do estimador, obtidos por krigagem $(A)$, inverso quadrado da distância $(B)$, modelos estatísticos $(C)$ e cokrigagem com altitude (D)

dezembro, apresentaram fraca correlação enquanto os demais períodos se situaram no nível moderado, significando que variações na variável primária (precipitação) podem ser razoavelmente explicadas por alterações na variável secundária (altitude).

A cokrigagem da precipitação, utilizando-se a altitude como variável secundária (CA), resultou em erro médio de 


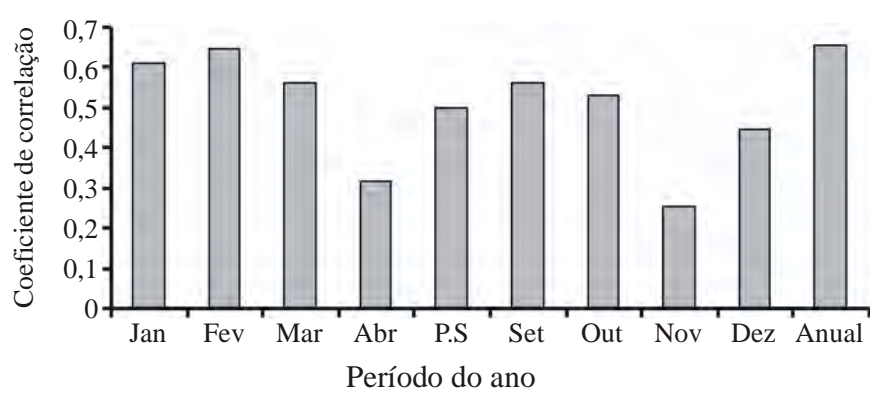

Figura 6. Coeficiente de correlação entre precipitação e altitude para os períodos estudados

$12,96 \%$, inferior ao das demais metodologias. Analisandose individualmente os períodos em estudo, tem-se que este interpolador produziu menores erros em março, período seco, outubro, novembro e anual, com valores de 12,32; 18,69; 13,$73 ; 10,74$ e $8,41 \%$, respectivamente. Lloyd (2005) avaliou o efeito da integração da elevação na estimativa da precipitação mensal na Grã-Bretanha, com o objetivo de checar se esta consideração produz estimativas mais acuradas que métodos de interpolação tradicionalmente utilizados de uma variável primária; para isto, o autor avaliou as metodologias krigagem simples com média variando localmente, modelos estatísticos e krigagem com tendência externa, nas quais a elevação foi utilizada como variável secundária, e o inverso do quadrado da distância e krigagem ordinária. $\mathrm{O}$ autor concluiu pela validação cruzada, melhor desempenho da krigagem com tendência externa nos meses de março a dezembro, e da krigagem ordinária em janeiro e fevereiro. Carrera-Hernández \& Gaskin (2007), em análise sobre o comportamento espaço-temporal da precipitação em uma bacia do México, avaliaram os interpoladores krigagem ordinária, krigagem com tendência externa, krigagem em bloco com tendência externa, krigagem ordinária na vizinhança local e krigagem com tendência externa na vizinhança local, e concluíram que o uso da elevação como variável secundária aperfeiçoou a variação espacial do mapeamento da precipitação e então recomendaram o uso da krigagem com tendência externa na vizinhança local. Martinez-Cob (1996), analisando a acurácia de interpoladores geoestatísticos na espacialização da precipitação média anual em regiões montanhosas no Norte da Espanha, avaliou os interpoladores krigagem ordinária, cokrigagem ordinária utilizando a altitude como variável secundária e krigagem residual modificada, obtendo menores erros absolutos e quadráticos com a cokrigagem. Todos esses resultados estão em consonância com os obtidos neste estudo e atestam a potencialidade da incorporação da elevação na espacialização da precipitação, em especial em regiões com elevada concentração de chuvas e período seco característico.

Em conjunto com o erro de estimativa, quantificou-se a tendência média dos estimadores; referida avaliação é de extrema importância uma vez que, tendo sido mensurado o erro de estimativa, resta saber se o interpolador proporcionou superestimava ou subestimativa dos dados. Pode-se observar, na Figura 5, comportamento predominante de superestimativa entre as metodologias, com exceção do mês de setembro, pelo modelo estatístico desenvolvido por Mello \&

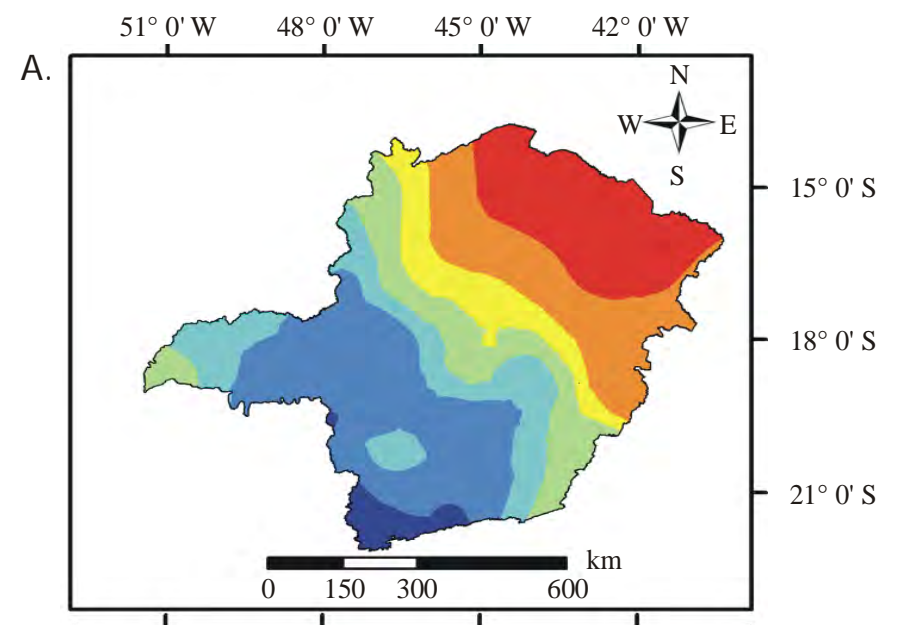

B.

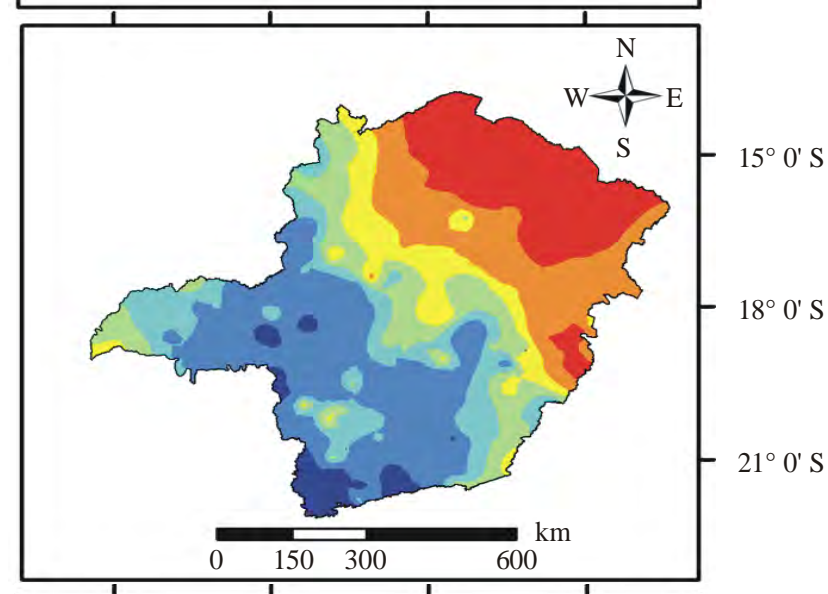

C.

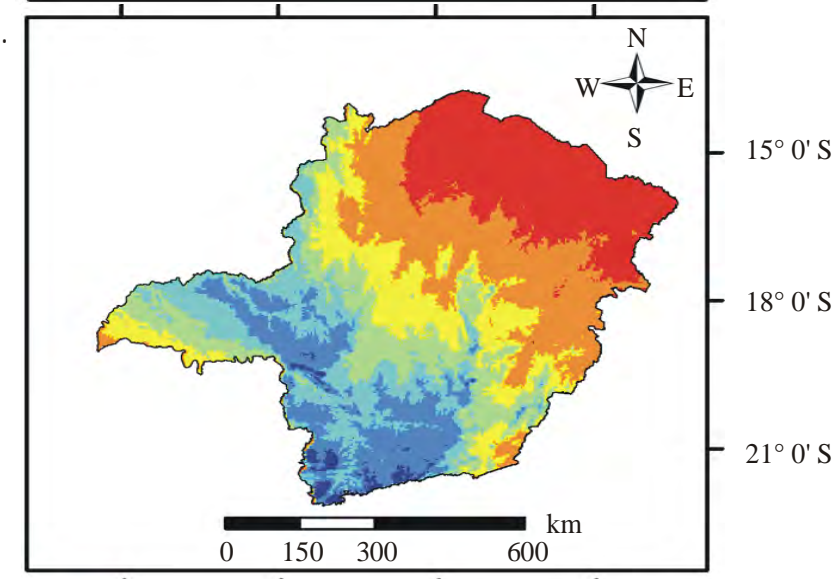

D.

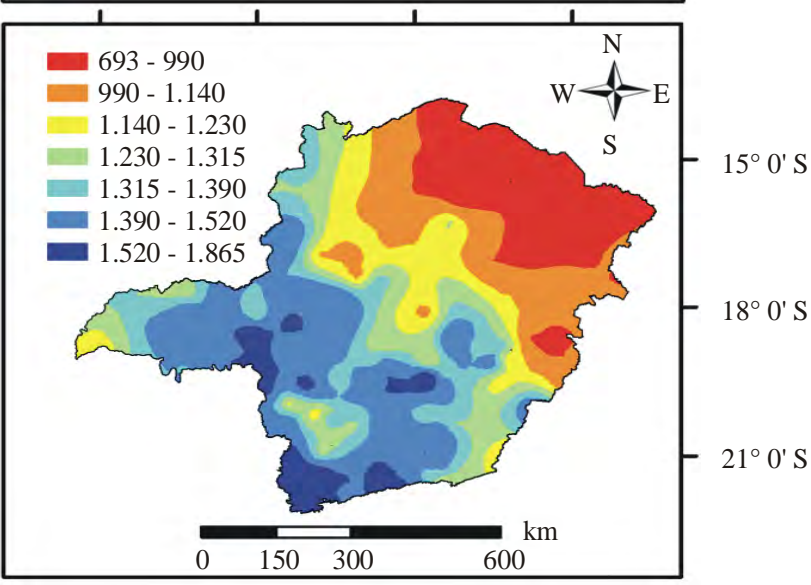

Figura 7. Mapas de precipitação média anual no Estado de Minas Gerais, obtidos por krigagem (A), IQD (B), ME (C) e cokrigagem (D) 
Silva (2009) que, em média, subestimou a precipitação desse período em $2,24 \%$ porém a avaliação da tendência média dos interpoladores apontou valores de 3,83; 3,91; 12,28 e $3,79 \%$ para os interpoladores krigagem, IQD, ME e cokrigagem, respectivamente, reforçando os resultados anteriores de melhor desempenho da cokrigagem. Uma constatação relevante está relacionada ao período no qual se obtiveram os valores extremos de tendência que, de forma análoga ao erro de estimativa, ocorreu em meses secos, nos quais houve maior dispersão dos índices pluviométricos ao longo do Estado. A tendência máxima foi obtida em abril, pela krigagem $(8,31 \%)$ e CA $(9,07 \%)$, outubro pelo IQD $(8,20 \%)$, e no período seco por ME $(50,67 \%)$.

Pela visualização dos mapas gerados a partir das metodologias de interpolação, pode-se obter uma avaliação que, embora subjetiva, expressa grande importância, uma vez que consiste no produto final do processo de interpolação. $\mathrm{Na}$ Figura 7 estão apresentados os mapas de precipitação média anual para o Estado de Minas Gerais, obtidos por krigagem (A), IQD (B), ME (C) e cokrigagem (D), classificados, de maneira semelhante, em 7 classes de valores.

Nota-se, de forma geral, distribuição espacial da precipitação semelhante nos mapas, com valores variando de forma decrescente no sentido Sul-Norte do Estado; contudo, quando a análise é realizada em termos regionais nos mapeamentos obtidos por IQD, ME e cokrigagem, pode-se visualizar maior detalhamento da distribuição espacial da precipitação ao longo do Estado, em comparação com os mapas gerados por IQD e krigagem indicando, então, maior sensibilidade na reconstituição da distribuição espacial da precipitação média anual. Uma análise importante adicional que pode ser desenvolvida da Figura 7(C, D) se liga ao fato de que se percebe clara influência do relevo na estimativa dos índices pluviométricos, uma vez que o primeiro traz a altitude como variável independente nos modelos e o segundo, como variável secundária no processo de cokrigagem demonstrando a relevância da altitude para estimativa da precipitação pluvial.

\section{CONCLUSÕES}

1. O erro absoluto médio gerado pela validação cruzada apontou melhor desempenho do modelo exponencial ajustado pelo método dos mínimos quadrados ponderados na espacialização da precipitação média mensal, período seco e anual, no Estado de Minas Gerais.

2. Todas as metodologias de interpolação avaliadas produziram erros aceitáveis, em se tratando do mapeamento de variáveis climáticas; entretanto, a cokrigagem, utilizando a altitude como variável secundária, resultou em menores erros em 5 dos 10 períodos analisados sendo indicada, então, para o mapeamento da precipitação pluvial no Estado de Minas Gerais.

3. A altitude mostrou-se relevante como variável secundária no processo de interpolação espacial, devendo ser incorporada à análise para obtenção de mapeamentos mais precisos e realistas da precipitação pluvial.

\section{LITERATURA CITADA}

Angélico, J. C. Desempenho da cokrigagem na determinação da variabilidade de atributos do solo. Revista Brasileira de Ciência do Solo, v.30, n.6, p.931-936, 2006.

Antunes, F. Z. Caracterização climática do estado de Minas Gerais. Informe Agropecuário, v.12, p.9-17, 1986.

Assad, E. D.; Macedo, M. A.; Zullo Júnior, J.; Pinto, H. S.; Brunini, O. Avaliação de métodos geoestatísticos na espacialização de índices agrometeorológicos para definir riscos climáticos. Pesquisa Agropecuária Brasileira, v.38, n.2, p.161-171, 2003.

Carrera-Hernández, J. J.; Gaskin, S. J. Spatial-temporal analysis of daily precipitation and temperature in the Basin of México. Journal of Hydrology, v.336, p.231-249, 2007.

Carvalho, J. R. de; Assad, E. D. Análise espacial da precipitação pluviométrica no estado de São Paulo: Comparação de métodos de interpolação. Engenharia Agrícola, v.25, n.2, p.377-384, 2005.

Carvalho, J. R. P. de; Queiroz, E. F. de. Uso de cokrigagem colocalizada na determinação da distribuição espacial de precipitação. Campinas: EMBRAPA, 2002. 4p. Boletim Técnico

Carvalho, J. R. P. de; Vieira, S. R.; Vendrusculo, L. G. Uso da técnica de mínimos quadrados ponderados para ajuste de modelos as semivariograma., Campinas: Embrapa Informática Agropecuária, 2004. 15p. Boletim de Pesquisa e Desenvolvimento.

Cecílio, R. A.; Pruski, F. F. Interpolação dos parâmetros da equação de chuvas intensas com uso do inverso de potências da distância. Revista Brasileira de Engenharia Agrícola e Ambiental, v.7, n.3, p.501-504, 2003.

ESRI - Environmental Systems Research Institute. ArcGIS 9: Getting started with ArcGIS. Redlands: ESRI, 2004. 265p.

Fenille, M. C.; Cardim, M. Correlação espacial entre a altitude e as precipitações pluviométricas no estado de São Paulo. Geociências, v.26, n.2, p.135-141, 2007.

Junqueira Junior, J. A.; Silva, A. M. da; Mello, C. R. de; Pinto, D. B. F. Continuidade espacial de atributos físico-hídricos do solo em sub-bacia hidrográfica de cabeceira. Ciência e Agrotecnologia, v.32, p.914-922, 2008.

Lloyd, C. D. Assessing the effect of integrating elevation data into the estimation of monthly precipitation in Great Britain. Journal of Hydrology, v.308, p.128-150, 2005.

Martinez-Cob, A. Multivariete geostatistical analysis of evapotranspiration and precipitation in mountainous terrain. Journal of Hydrology, v.174, p.19-35, 1996.

Mello, C. R. de.; Lima, J. M.; Silva, A. M.; Mello, J. M.; Silva, M. S. Krigagem e inverso do quadrado da distância para interpolação dos parâmetros da equação de chuvas intensas. Revista Brasileira de Ciência do Solo, v.27, n.5, p.925-933, 2003.

Mello, C. R. de; Sá, M. A. C.; Curi, N.; Mello, J. M.; Viola, M. R.; Silva, A. M. da. Erosividade mensal e anual da chuva no Estado de Minas Gerais. Pesquisa Agropecuária Brasileira, v.42, p.537-545, 2007.

Mello, C. R. de; Silva, A. M. Modelagem da precipitação mensal, anual e do período seco no Estado de Minas Gerais. Revista Brasileira de Engenharia Agrícola e Ambiental, v.13, n.1, p.68-74, 2009. 
Mello, C. R. de; Viola, M. R.; Silva, A. M.; Mello, J. M. Continuidade espacial de chuvas intensas no estado de Minas Gerais. Ciência Agrotecnologia, v.32, n.2, p.532-539, 2008.

Mello, J. M.; Batista, J. L. F.; Oliveira, M. S. de; Ribeiro Júnior, P. J. Estudo da dependência espacial de características dendrométricas para Eucalyptus grandis. CERNE, v.11, n.2, p.113-126, 2005. Ribeiro Jr., P. J.; Diggle, P. P. GeoR: A package for geoestatistical analysis. R-News. Rochester, v.1, n.2, p.15-18, 2001.
Santos, C. Estatística descritiva - Manual de auto-aprendizagem. 1.ed. Lisboa: Edições Silabo, 2007. 264p.

Vieira, S. R. Geoestatística em estudos de variabilidade espacial do solo: Tópicos em ciência do solo. Viçosa: Sociedade Brasileira de Ciência do Solo, 2000. p.1-54.

Watson, D. F.; Philip, G. M. A Refinement of inverse distance weighted interpolation. Geoprocessing, v.2, p.315-327, 1985. 